西

\title{
BONE MINERAL DENSITY EVOLUTION AFTER PARATHYROIDECTOMY IN PATIENTS WITH PRIMARY HYPERPARATHYROIDISM
}

\section{A. Vicuña, A. M. Ramos Leví, M. Sampedro, S. Campos, M. Zelada, Á. Maíllo, A. Mossé, M. Marazuela.}

\section{Department of Endocrinology and Nutrition. Hospital Universitario de la Princesa. Madrid.}

\section{INTRODUCTION}

Primary hyperparathyroidism results in increased bone resorption. The presence of osteoporosis is at present an established surgery criteria.

The aim of this study was to evaluate the changes in bone mineral density (BMD) after surgery in patients with primary hyperparathyroidism.

\section{MATERIAL AND METHODS}

Retrospective study of 58 patients with primary hyperparathyroidism treated by parathyroidectomy (PTX) from 2004 to 2012. We analyzed the percent change in BMD of spine, femoral neck and distal radius densitometry, 12 and 36 months after surgery.

\section{RESULTS}

Among the 58 patients enrolled, we obtained densitometry data of 26 patients after 12 months and 37 after 36 months. The average age of the patients was $61 \pm 12$ years and $70.7 \%$ were women (Figure 1). Baseline and one year after the parathyroidectomy biochemical characteristics are shown in Table 1.

We observed an increased BMD at lumbar spine and femoral neck one year after surgery $(+2.3 \% \pm 5.1, p=0.027 ;+5.7 \%$ $\pm 6.3, p=0.000$, respectively). Improvement at 36 months was also observed in both locations $(+4.9 \% \pm 7.4, p=0.001$; $+8.5 \% \pm 6.0, p=0.000$ ) (Figure 3). At the distal third of the radius, there were no changes in BMD in any of the follow-up times, although a slight increase at 36 months was observed. $(+0,96 \% \pm 4,2, p=0,576)$. Sixteen of the 58 patients $(27.6 \%)$ also were treated with bisphosphonates. There were no differences in changes of BMD between these patients and those who did not received bisphosphonates (Figure 4).

\begin{tabular}{|c|rl|r|c|c|}
\hline & \multicolumn{2}{|c|}{ Baseline } & \multicolumn{2}{|c|}{12 months } & $p$ \\
\hline Calcium $(\mathrm{mg} / \mathrm{dll})$ & $\mathbf{1 0 , 8}$ & $\mathbf{0 , 7}$ & $\mathbf{9 , 1}$ & $\mathbf{0 , 8}$ & 0,000 \\
\hline PTH $(\mathrm{pg} / \mathrm{ml})$ & 147,3 & $\mathbf{8 6 , 2}$ & $\mathbf{7 0 , 4}$ & $\mathbf{3 3 , 3}$ & 0,000 \\
\hline Vitamin D $(\mathrm{ng} / \mathrm{ml})$ & $\mathbf{3 7 , 8}$ & $\mathbf{1 7}$ & $\mathbf{3 5 , 9}$ & $\mathbf{1 3 , 5}$ & $\mathbf{0 , 5 7 9}$ \\
\hline
\end{tabular}

Table 1. Biochemical characteristics before and 12 months after the PTX.

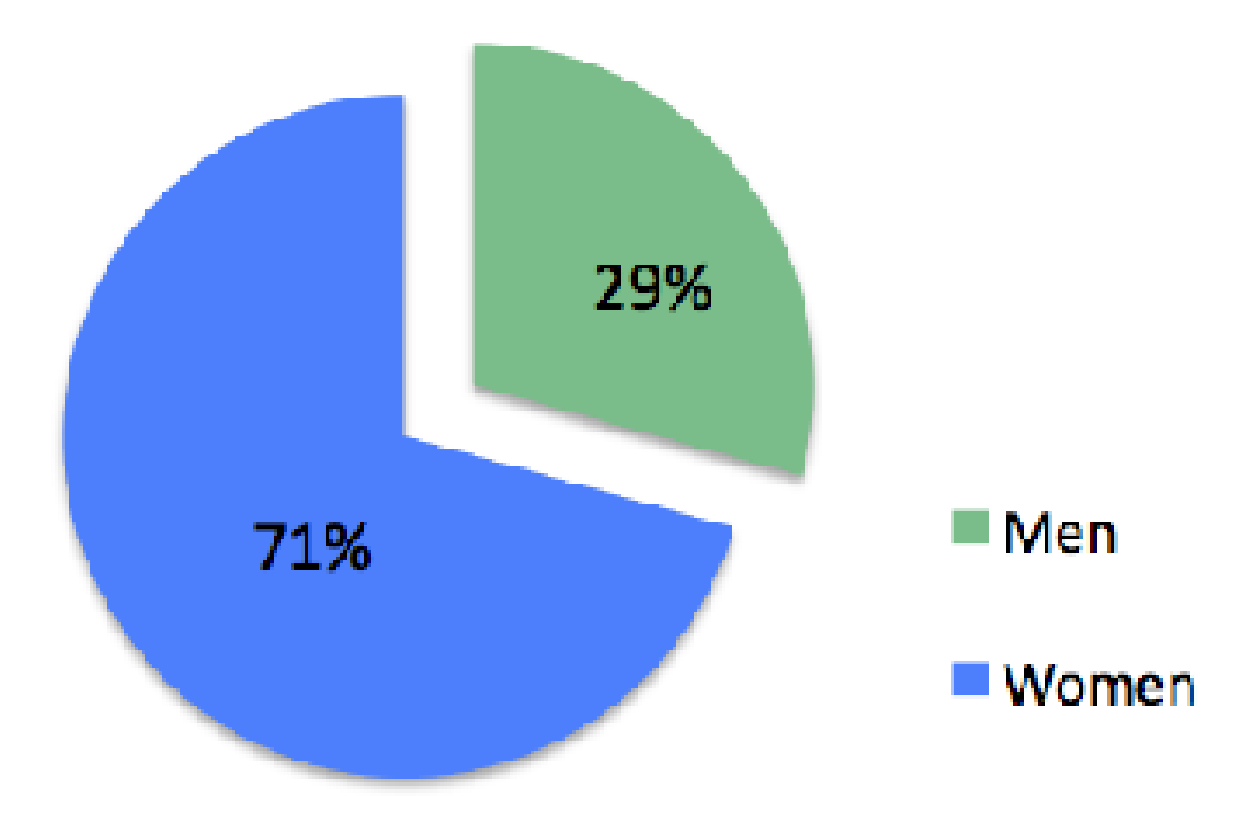

Figure 1. Sex distribution of the studied patients.

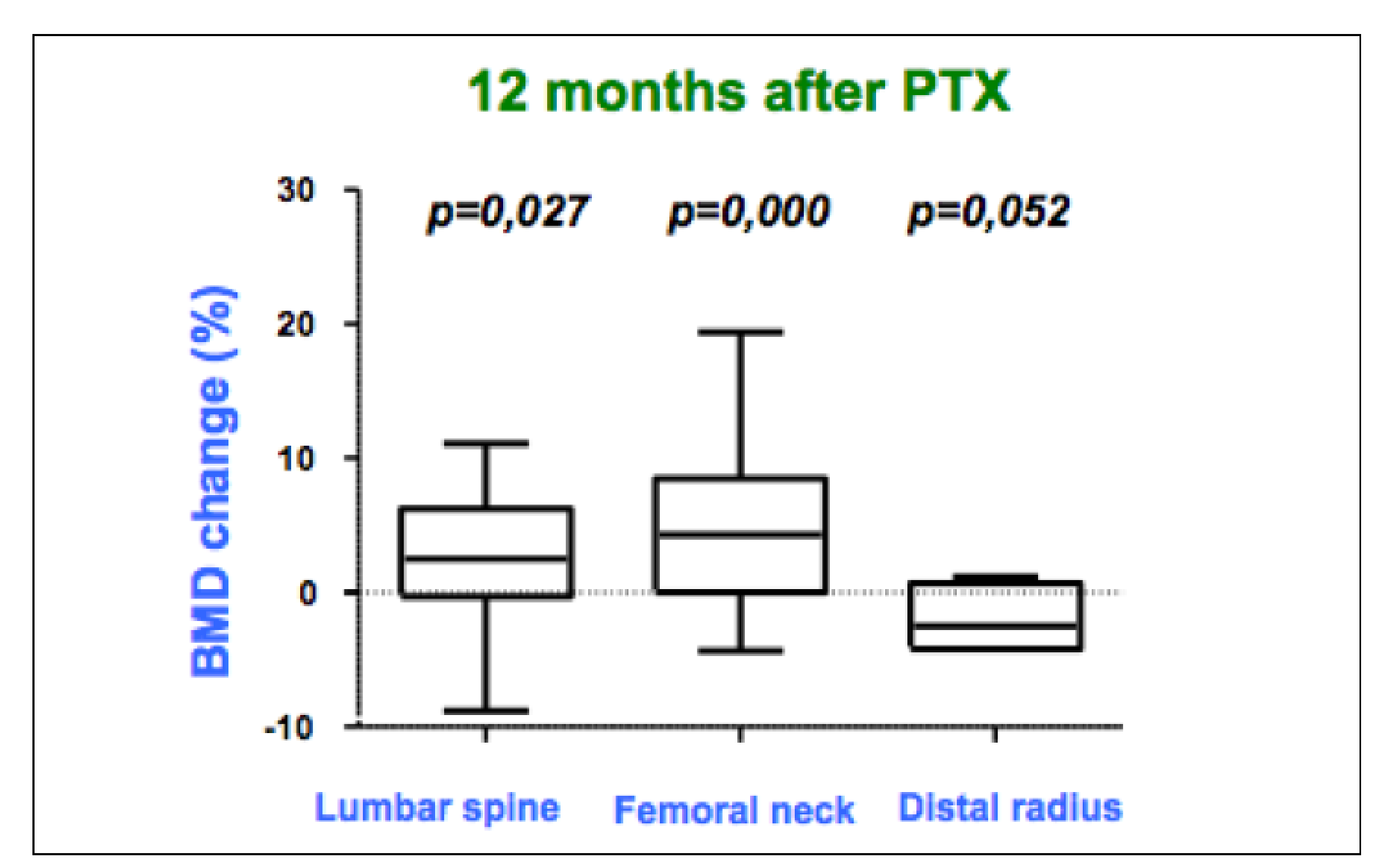

Figure 2. BMD percent change 12 months after PTX.

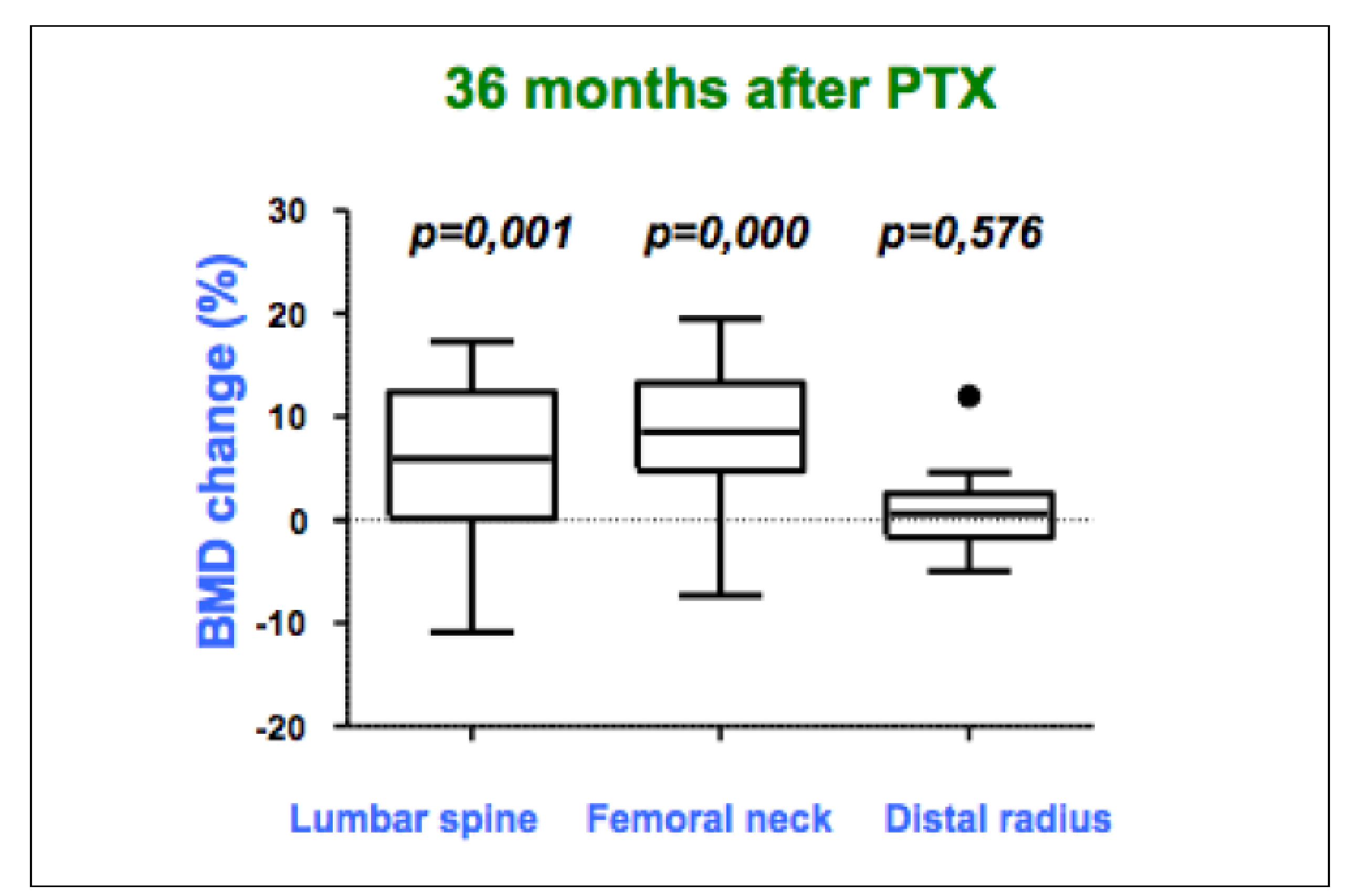

Figure 3. BMD percent change 36 months after PTX
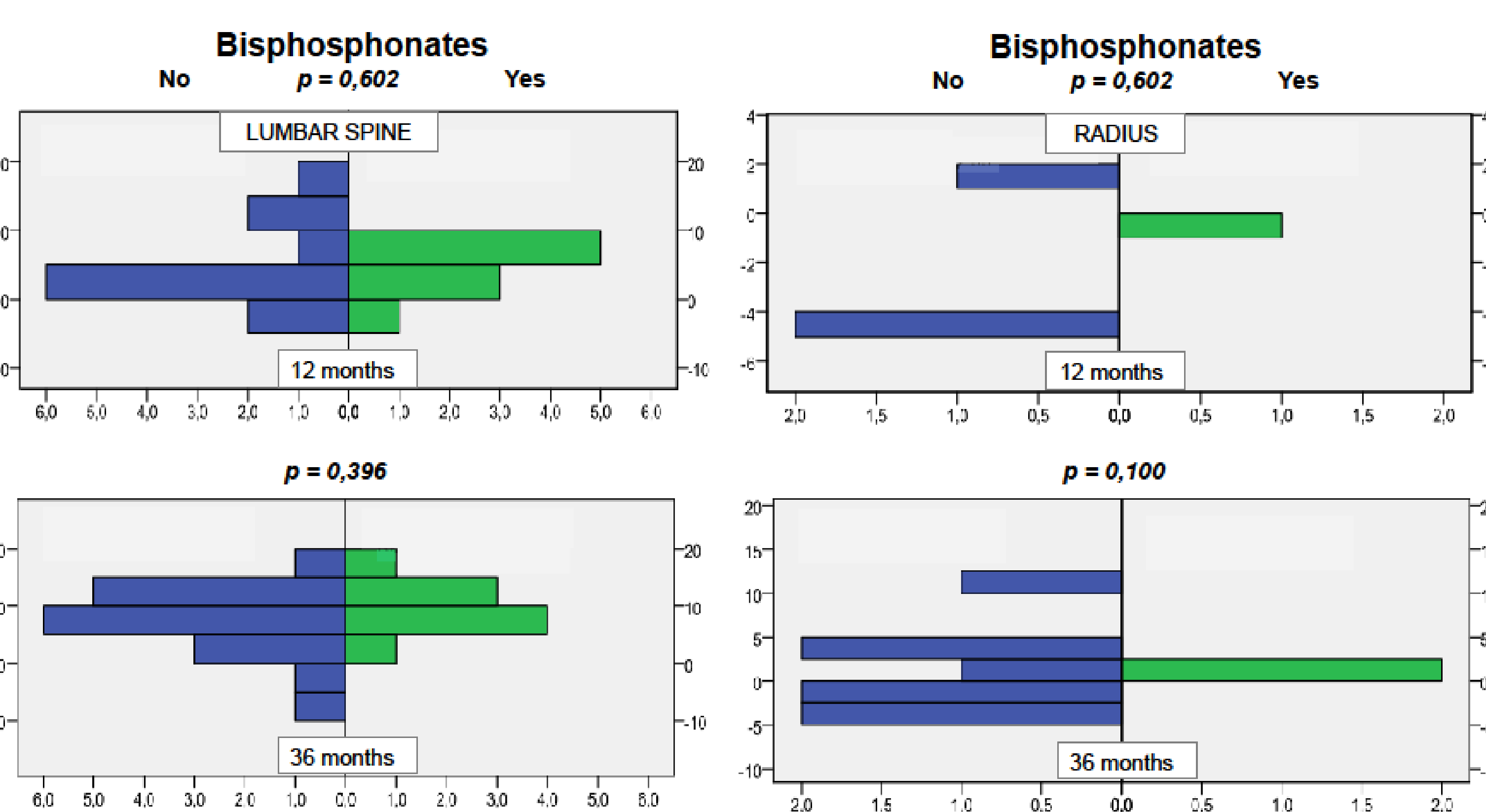

Figura 4. Comparison of BMD percent change at femoral neck, lumbar spine and distal radius at 12 and 36 months after PTX depending on the concomitant bisphosphonates therapy (Mann-Whitney U test).

\section{CONCLUSION}

Femoral neck and spine BMD improved one and two years after surgery in patients whit primary hyperparathyroidism. It would be interesting to evaluate the response to longer term. 